\title{
Comparative Evaluation of Elevation, Keratometric, Pachymetric and Wavefront Parameters in Normal Eyes, Subclinical Keratoconus and Keratoconus with a Dual Scheimpflug Analyzer
}

\author{
David Smadja, David Touboul, Joseph Colin
}

\begin{abstract}
Purpose: To compare the corneal parameters in normal corneas, forme fruste keratoconus (FFKC) and keratoconus measured with a dual Scheimpflug analyzer.
\end{abstract}

\begin{abstract}
Materials and methods: A total of 372 eyes of 197 patients were prospectively enrolled in the study and divided into three groups: 148 eyes of 102 patients with keratoconus, 47 contralateral topographically normal eyes of clinically evident keratoconus in the fellow eye and 177 eyes of 95 refractive surgery candidates with normal corneas. All eyes were measured with a dual Scheimpflug analyzer and elevation, keratometric, pachymetric and wavefront data were analyzed. Mean and intergroup comparisons were performed for 43 parameters.
\end{abstract}

Results: Eighty-eight percent of the parameters analyzed (38/43) were significantly different between normal and keratoconus whereas it was less than $40 \%$ (17/43) between normal and FFKC. The majority of the elevation parameters were significantly different between normal eyes and FFKC $(11 / 14)$ whereas the I-S value and the $K_{\max }$ were the only two parameters related to the anterior curvature that were significantly different between both groups. Corneal vertical coma was the only corneal aberrations significantly different between normal and FFKC ( $p<0.07)$.

Conclusion: The dual Scheimpflug analyzer provides useful parameters for differentiating normal corneas, FFKC and keratoconus.

Keywords: GALILEI, Dual Scheimpflug, Keratoconus, Forme fruste keratoconus, Corneal elevation, Posterior surface, Pachymetry, Wavefront profile, Placido disk.

How to cite this article: Smadja D, Touboul D, Colin J. Comparative Evaluation of Elevation, Keratometric, Pachymetric and Wavefront Parameters in Normal Eyes, Subclinical Keratoconus and Keratoconus with a Dual Scheimpflug Analyzer. Int J Kerat Ect Cor Dis 2012;1(3):158-166.

\section{Source of support: Nil}

Conflict of interest: None declared

\section{INTRODUCTION}

Identifying corneas with risk of developing iatrogenic ectasia after laser-assisted in situ keratomileusis (LA SIK) remains the major concern of the preoperative refractive surgery screening. Recent technological advances in anterior segment imaging enabled to sensitively detect keratoconus, however, the detection of subclinical keratoconus and its differentiation from normal eyes still remains a challenge with the current keratoconus detection programs. While corneal topography has been found sensitive for detecting keratoconus prior to clinical biomicroscopic findings, recent studies have pointed out the significant role of corneal epithelium in reducing corneal topographic irregularities ${ }^{1}$ and in masking the presence of an underlying cone on the anterior surface in early keratoconus. ${ }^{2,3}$ In contrast, several corneal indices derived from corneal tomography technology, which allows for a more extensive analysis of the corneal properties, have been recently reported for improving the sensitivity of the subclinical keratoconus detection. $V$ arious corneal indices and cutoff values derived from elevation, ${ }^{4}$ thickness profile ${ }^{5,6}$ or wavefront ${ }^{7}$ have been extensively studied and reported with different imaging technologies, such as the 0 rbscan II z system ${ }^{4}$ the Pentacam ${ }^{8}$ and the Sirius system. ${ }^{9}$ However, to our knowledge, there is to date, no report comparing the corneal features of normal, keratoconic and subclinical keratoconic corneas using the dual Scheimpflug analyzer. The GALILEI analyzer (Ziemer O phthalmic Systems A G; Port, Switzerland) is a relatively new dual Scheimpflug imaging system combined with Placido disk technology, which allows for a large evaluation of the corneal features. Therefore, the aim of this study was first to compare elevation, keratometric, pachymetric and wavefront parameters in normal corneas, subclinical keratoconus and keratoconus and attempting to highlight the most relevant parameters for differentiating these corneas.

\section{MATERIALS AND METHODS}

This prospective and comparative study was conducted at the $U$ niversity H ospital of B ordeaux, France, in the $\mathrm{N}$ ational Reference Center for K eratoconus (CRNK) and approved by the Institutional Review Board of our institution. The study was conducted in accordance with the tenets of the Declaration of Helsinki.

\section{Subjects}

A total of 372 eyes of 197 patients were prospectively enrolled in the study and imaged with the GALILEI Dual Scheimpflug A nalyzer System. Corneas were then classified 
into three groups based on eyes conditions: Normal (group 1) included 177 eyes of 95 subjects, forme fruste of keratoconus (FFK C, group 2) included 47 eyes of 47 patients and keratoconus (group 3), included 148 eyes of 102 patients. Groups were defined as follow:

Group 1: Normal eyes were enrolled among suitable candidates undergoing a screening examination for refractive surgery and among general population undergoing a routine ophthalmological examination. All patients had discontinued daily-wear soft contact lens use at least 1 week before evaluation. Eyes were considered normal when no clinical signs of keratoconus and no suggestive topographic or tomographic patterns of suspect keratoconus were found, such as asymmetric bow tie (AB) with a skew ed radial axis (SRAX), focal or inferior steepening, central keratometry greater than $47.0 \mathrm{D}$ or corneas thinner than $500 \mu \mathrm{m}$. Exclusion criteria for this group were: Previous ocular surgery, ocular pathology, familial history of keratoconus and contact lens wearing in the past week.

Group 2: It was composed of 47 FFKC, which are defined as the contralateral eyes of clinically evident keratoconus in the fellow eye ( $n=47)$. These eyes had no clinical signs of keratoconus and a normal topographical aspect with no $A B$ and no focal or inferior steepening pattern. This condition is also known in the literature as 'subclinical keratoconus' since it has already been reported that approximately $50 \%$ of clinically normal fellow eyes of patients with a unilateral keratoconus progressed to keratoconus within 16 years with a greater risk during the first 6 years of onset. ${ }^{10}$

Group 3: Eyes with keratoconus were enrolled among patients that were referred to the NRCK for a regular control visit for moderate to advance keratoconus. Diagnosis of clinical keratoconus was previously defined and includes a combination of findings characteristics of keratoconus: ${ }^{11,12}$ Corneal topography with A B pattern or localized steepening, irregular cornea determined by distortion of the retinoscopic or ophthalmoscopic red reflex and at least one of the following slit-lamp findings: Stromal thinning, Fleischer ring greater than $2 \mathrm{~mm}$ arc, $V$ ogt striae and corneal scarring consistent with keratoconus. Eyes that wear contact lenses and eyes that have al ready underwent a specific treatment for keratoconus, such as collagen cross-linking, intracorneal rings or keratoplasty, as well as marginal pellucid degeneration were excluded from the study.

\section{Dual Scheimpflug Analyzer System and Procedure}

M easurements were performed with the GALILEI analyzer system (software version 5.2.1) according to the manufacturer's guidelines: The device was first brought into focus (Placido rings into sharp focus) and aligned with the patient visual axis (central fixation light). Then, patients were asked to blink just before the measurement. Only measurements that satisfy the minimum quality required by the system were included in this study.

The GALILEI is a rotating Scheimpflug tomography based device combining dual-channel Scheimpflug cameras and a Placido disk. The system acquires between 15 and 60 Scheimpflug images per scan and two Placido top view images at $90^{\circ}$ apart, as the cameras rotate around the central axis. Placido and Scheimpflug data are acquired simultaneously, and then a motion correction algorithm is applied to the combined dataset. This correction compensates for patient's eye motion during scanning by a tracker that locates and tracks a patch on the iris, matching its location on every scan.

Simultaneously, the system allows for a corneal aberration analysis separately from the aberrations of the lens and displays the total higher order corneal wavefront aberrations calculated from the front and back surface. B oth the displayed wavefront maps and the RMS indices are recalculated recentered on the pupil center over a $6.0 \mathrm{~mm}$ optical zone. Individual Zernike coefficients for terms from 2nd to 6 th order are displayed in microns as well as in diopters.

\section{Analyzed Parameters and Description}

All eyes were imaged with the GALILEI analyzer and patients had a detailed preoperative ophthalmic evaluation including uncorrected visual acuity (UCVA), best spectaclecorrected visual acuity (BSCVA) using Early Treatment Diabetic R etinopathy Study charts, manifest refraction, sl itlamp evaluation, applanation tonometry and fundus examination. Forty-three variables were recorded and are listed in Table 1. Briefly, the analyzed parameters can be described as follow:

\section{Curvature Derived Parameters}

Simulated keratometries (SimK) are calculated with the socalled keratometric index, which is 1.3375 , to compensate for the effect of the posterior corneal surface and are derived from the axial curvature map. SimK steep (SimK s) and SimK flat (SimK f) are calculated from the pair of meridians $90^{\circ}$ apart with the greatest difference in average power, from 0.5 to $2.0 \mathrm{~mm}$ distance from the center. The magnitude of the astigmatism results from the difference between the steepest $K$ and the flattest $K$, and the axis value was the direction of the meridian of the steepest axis.

$\mathrm{K}_{\max }$ has been directly recorded from the curvature map and represents the maximal keratometric value, which is 


\begin{tabular}{|c|c|c|c|c|}
\hline $\begin{array}{l}\text { Curvature-derived } \\
\text { parameters }\end{array}$ & $\begin{array}{l}\text { Elevation-derived } \\
\text { parameters }\end{array}$ & $\begin{array}{l}\text { Wavefront-derived } \\
\text { parameters }\end{array}$ & $\begin{array}{l}\text { Pachymetric-derived } \\
\text { parameters }\end{array}$ & $\begin{array}{l}\text { Other parameter } \\
\text { age }\end{array}$ \\
\hline $\begin{array}{l}\text { Anterior data: } \\
\mathrm{K}_{\max } \\
\text { Axial SimKs, Kf, Cyl } \\
\text { Axial MeanK }(0-4 \mathrm{~mm}) \\
\text { Tang MeanK }(4-7 \mathrm{~mm}) \\
\text { Tang MeanK }(7-10 \mathrm{~mm}) \\
\text { Eccentricity }\left(\varepsilon^{2}\right) \\
\text { I-S value }\end{array}$ & $\begin{array}{l}\text { Anterior data: } \\
\text { With BFTA: } \\
\text { Max elevation TP } \\
\text { Max elevation } \mathrm{K}_{\max } \\
\text { Max elevation } \\
\text { With BFS: } \\
\text { Max elevation TP } \\
\text { Max elevation } \mathrm{K}_{\max } \\
\text { Max elevation } \\
\text { AAI } \\
\text { Posterior data: } \\
\text { With BFTA: } \\
\text { Max elevation TP } \\
\text { Max elevation } \mathrm{K}_{\max } \\
\text { Max elevation } \\
\text { With BFS: } \\
\text { Max elevation TP } \\
\text { Max elevation } \mathrm{K}_{\max } \\
\text { Max elevation AAI }\end{array}$ & $\begin{array}{l}\text { RMS total corneal HOA } \\
\text { RMS corneal SA } \\
\text { RMS corneal vertical coma } \\
\text { RMS corneal horizontal coma } \\
\text { RMS total corneal coma } \\
\text { Corneal power (CP) } \\
\text { Total corneal power (0-4 mm) } \\
\text { Total corneal power }(4-7 \mathrm{~mm}) \\
\text { Total corneal power }(7-10 \mathrm{~mm})\end{array}$ & $\begin{array}{l}\text { Thinnest point } \\
\text { Corneal volume } \\
\text { Biometric-derived } \\
\text { parameters } \\
\text { Anterior chamber depth } \\
\text { Anterior chamber volume }\end{array}$ & \\
\hline
\end{tabular}

Ks: Steepest K; Kf: Flattest K; Cyl: Cylinder (D); MeanK: Average keratometry (D); I-S: Inferior-superior; ISPS: I-S posterior score; DSI: Differential sector index; SAI: S urface asymmetry index; OSI: O pposite sector index; SRI: Surface regularity index; CSI: Central/surround index; IAI: Irregular astigmatism index; ACP: Average central power; AA: Area analyzed; SDP: Standard deviation power; BFTA: Best fit toric aspheric sphere; BFS: Best fit sphere; TP: Thinnest point; KAI: Kranneman arce index; HOA: Higher order aberrations; SA: S pherical aberrations

often located in paracentral or peripheral cornea, at the top of the cone in keratoconic corneas, and therefore underestimated by the simulated steepest keratometry value, which is calculated only over the central cornea $(0-4 \mathrm{~mm})$.

$M$ ean keratometry ( $M$ eanK ) is the average keratometry calculated over the analyzed area, central (0-4 mm), paracentral $(4-7 \mathrm{~mm})$ or peripheral $(7-10 \mathrm{~mm})$ cornea. These values are derived from the axial curvature maps for the central cornea and from the tangential curvature maps for the paracentral and peripheral cornea. Since the axial curvature is highly dependent on the position of the reference axis, the use of axial radius of curvature could lead to underestimate areas of relative high curvature (keratoconus) and overestimate areas of relative lower curvature, especially in paracentral and peripheral cornea. However, tangential curvature is calculated using the real radius of curvature in a precise point of the map. Therefore, we decided to use the values derived from the tangential curvature map, for the areas between 4 and $10 \mathrm{~mm}$ in order to minimize bias in the measurement of the peripheral corneal curvature, which is well known to be the most critical area for detecting a keratoconus.

Eccentricity $\left(\varepsilon^{2}\right)$ is one of the four parameters by which the shape of a conic section can be described.
Q (asphericity), p-value and E (corneal shape factor) are the others. These terms are mathematically related by the following equation: $\varepsilon^{2}=E=1 p=-Q$. It is calculated within a central diameter of $8 \mathrm{~mm}$ averaged over all meridians of the anterior corneal surface. A positive value refers to a prolate shape of the corneal surface whereas a negative value refers to an oblate shape.

I-S value is the amount of steepening of the inferior cornea compared with that of the superior cornea. It is calculated by subtracting the superior value from the inferior value. The inferior value was calculated by averaging 5 data points al ong the inferior cornea $3.0 \mathrm{~mm}$ from the center of the cornea at $30^{\circ}$ intervals (i.e. at 210,240,270, 300 and $\left.330^{\circ}\right)$. The superior value was derived from averaging 5 points on the superior cornea $3.0 \mathrm{~mm}$ from the center of the cornea (i.e. at 30,60, 90, 120 and $150^{\circ}$ ).

Posterior curvature data ( $\left.\mathrm{Ks}, \mathrm{Kf}, \mathrm{Cylinder,} \mathrm{MeanK}, \varepsilon^{2}\right)$ are basically the same as for the anterior surface, the only difference is that the keratometries values $(K s, K f)$ are not simulated since they are calculated with the real indices of refraction of the cornea $(1,376)$ and the aqueous humor $(1,336)$.

I-S Posterior Score (ISPS) has been designed over the course of the study for evaluating the asymmetry of the 
Comparative Evaluation of Elevation, Keratometric, Pachymetric and Wavefront Parameters in Normal Eyes

posterior surface. It is calculated by first cal culating the I-S value of the posterior surface along with the superior and inferior cornea $3.0 \mathrm{~mm}$ from the center. The absolute value of the following formula corresponds to the ISPS:

$$
\text { ISPS }=(\text { Posterior I-S ratio }-1) \times 1000
$$

\section{Elevation-derived Parameters}

Elevation values were measured with two different reference bodies over an $8 \mathrm{~mm}$ calculation zone: The best-fit sphere (BFS) in float mode and the best-fit toric and aspheric body (BFTA ). V alues were recorded in both anterior and posterior surfaces over three locations by manually guiding the cursor over the anterior and posterior elevation maps: Highest elevation value within the $8 \mathrm{~mm}$ diameter zone (M AE and $M P E$ ), elevation value at the thinnest point (MAETP and M PETP) and elevation value at the $K_{\text {max }}$ location (M AEK $m$ and MPEK $\mathrm{m}$ ).

The quantification of asymmetry of asphericity of a corneal surface, the asphericity asymmetry index (A AI) has been proposed and described by A rce. ${ }^{13} \mathrm{It}$ is calculated over the BFTA map display as the absolute value of the difference between the maximum negative elevation value and maximum positive elevation value within the central $6 \mathrm{~mm}$ diameter data zone. This index has been recorded for the anterior and posterior surfaces.

\section{Corneal Wavefront-derived Parameters}

Total corneal HOA s root mean square (RM S) from the 3rd to the 6th order as well as the RM S spherical aberration $Z$ $(4,0)$, RM S vertical Z $(3,-1)$ and horizontal $Z(3,1)$ coma and RMS total coma through a $6 \mathrm{~mm}$ pupil size were recorded from the wavefront maps displayed in microns.

Enantiomorphism was neutralized by inverting the sign of the mirror-symmetric coefficients of the left eyes as shown in the following equations:

For all $C_{n}{ }^{m}$ if $n$ is even and $m<0: C_{n}{ }^{m}=-\left(C_{n}{ }^{m}\right)$

For all $C_{n}{ }^{m}$ if $n$ is odd and $m>0: C_{n}{ }^{m}=-\left(C_{n}{ }^{m}\right)$

\section{Corneal Power-derived Parameters}

The average total corneal power (TCP) over three different corneal zones respectively, central (0-4 mm), paracentral (4-7 $\mathrm{mm})$ and peripheral $(7-10 \mathrm{~mm})$ were recorded. The TCP, which is calculated by the GALILEI system, is the actual power of the cornea including both the anterior and posterior surfaces. The TCP power and map are calculated by tracking the path of incident rays of light through the 3-dimensional (3D) cornea using ray tracing.

\section{Pachymetric and Biometric-derived Parameters}

The thinnest point of the cornea as well as the corneal and anterior chamber volume calculated over a diameter of $8.0 \mathrm{~mm}$ were recorded. A nterior chamber depth was calculated as the distance between the crystalline lens and the posterior cornea, measured along normals to the line between the outer iris endpoints.

\section{STATISTICAL ANALYSIS}

All calculations were performed with STATA/SE (StataCorp 2005, version 9.0, Texas, USA). In principle, p-values less than 0.05 were considered statistically significant. To correct for multiples testing, $p$-values were adjusted according to the Bonferroni-Holm procedure.

Part of the statistical analyses concerned the question of dependence between observations. Sincefor most patients the data included both eyes, it seemed plausible that there will be intraclass correlation within patient, so that the whole database cannot be considered as independent observations. Therefore, we initially used the mixed model rather than ANOV A for comparing group since mixed model takes account of the dependence among observations. However, results of this analysis indicated that there was no dependence so that the independence assumption was valid.

\section{RESULTS}

This study included 372 eyes of 197 subjects divided into three groups (normal, FFKC and keratoconus). Baseline clinical and demographic characteristics of the subjects by groups are summarized in Tables 2 to 5 .

\section{Normal vs Keratoconus}

Normal and keratoconic corneas were significantly different in nearly all of the 43 parameters ( $p<0.001)$, except in the biometric parameters, anterior chamber depth $(p=0.07)$ and anterior chamber volume $(p=0.4)$ as well as in peripheral mean keratometry ( $p=0.2)$, horizontal coma $(p=0.8)$ and age $(p=0.8)$ that was similar in both groups, with $28.8 \pm 8.6$ years old and $28.9 \pm 10$ years old, respectively in the normal group and keratoconic group. The intergroup comparisons and means are shown in Tables 3 to 5 .

\section{Normal vs FFKC}

There was no statistically significant difference between normal corneas and FFKC for 26 of the 43 analyzed parameters. A mong the 17 variables that were statistically different between both groups, elevation parameters were 
Table 2: Demographic characteristics of the subjects by groups

\begin{tabular}{lccc}
\hline Characteristics & Normal & FFKCN & KCN \\
\hline Eyes, $n$ & 177 & 47 & 148 \\
Subjects, $n$ & 95 & 47 & 102 \\
Age \pm SD & $28.9 \pm 8.6$ & $31.8 \pm 9.8$ & $28.9 \pm 10.0$ \\
Female sex (\%) & $105(59.3 \%)$ & $12(25.5 \%)$ & $48(32.4 \%)$ \\
\hline
\end{tabular}

FFKCN: Forme fruste keratoconus; KCN: Keratoconus; SD: Standard deviation

Table 3: Curvature-derived parameters and corneal power: Means and intergroup comparison

\begin{tabular}{|c|c|c|c|c|c|c|}
\hline \multirow[t]{3}{*}{ N (n subjects) } & \multicolumn{3}{|c|}{ Mean \pm SD (min; $\max )$} & \multicolumn{3}{|c|}{ Intergroup comparisons mixed model ( $p$-value) } \\
\hline & Normal & FFKCN & $\mathrm{KCN}$ & $\mathrm{N}$ vs FFKC & $\mathrm{N}$ vs $\mathrm{KCN}$ & FFKC VS KCN \\
\hline & $177(n=95)$ & $47(n=47)$ & $148(n=102)$ & & & \\
\hline \multicolumn{7}{|l|}{ Anterior surface } \\
\hline $\mathrm{K}_{\max }(\mathrm{D})$ & $\begin{array}{l}44.2 \pm 1.3 \\
(41.2 ; 46.9)\end{array}$ & $\begin{array}{l}45.4 \pm 1.7 \\
(41.7 ; 49.4)\end{array}$ & $\begin{array}{l}54.7 \pm 5.2 \\
(47 ; 76.6)\end{array}$ & 0.01 & $<0.001$ & $<0.001$ \\
\hline Axial SimKs (D) & $\begin{array}{l}44.0 \pm 1.3 \\
(40 ; 46.9)\end{array}$ & $\begin{array}{l}44.2 \pm 1.7 \\
(41.2 ; 48.9)\end{array}$ & $\begin{array}{l}48.9 \pm 4.3 \\
(39.2 ; 64.3)\end{array}$ & 0.5 & $<0.001$ & $<0.001$ \\
\hline Axial SimKf (D) & $\begin{array}{l}43.0 \pm 1.3 \\
(39.6 ; 46.4)\end{array}$ & $\begin{array}{l}42.9 \pm 1.5 \\
(38.4 ; 45.9)\end{array}$ & $\begin{array}{l}45.3 \pm 3.6 \\
(37.8 ; 59.9)\end{array}$ & 0.63 & $<0.001$ & $<0.001$ \\
\hline Cylinder (D) & $\begin{array}{l}0.94 \pm 0.6 \\
(0.11 ; 1.4)\end{array}$ & $\begin{array}{l}1.3 \pm 1 \\
(0.3 ; 5.5)\end{array}$ & $\begin{array}{l}3.6 \pm 2.2 \\
(0.35 ; 10.7)\end{array}$ & 0.31 & $<0.001$ & $<0.001$ \\
\hline Axial MeanK (0-4 mm) & $\begin{array}{l}43.5 \pm 1.3 \\
(39.8 ; 46.9)\end{array}$ & $\begin{array}{l}43.6 \pm 1.5 \\
(39.9 ; 46.6)\end{array}$ & $\begin{array}{l}47.4 \pm 4 \\
(38.2 ; 63.2)\end{array}$ & 0.55 & $<0.001$ & $<0.001$ \\
\hline Tang MeanK (4-7 mm) & $\begin{array}{l}41.6 \pm 1.4 \\
(38.4 ; 44.7)\end{array}$ & $\begin{array}{l}41.2 \pm 1.8 \\
(37.6 ; 44.8)\end{array}$ & $\begin{array}{l}40.6 \pm 2.7 \\
(33.8 ; 48)\end{array}$ & 0.23 & $<0.001$ & $<0.001$ \\
\hline Tang MeanK (7-10 mm) & $\begin{array}{l}39.6 \pm 1.8 \\
(33.5 ; 43.8)\end{array}$ & $\begin{array}{l}38.5 \pm 2.1 \\
(33 ; 43)\end{array}$ & $\begin{array}{l}38.6 \pm 3.6 \\
(29.9 ; 49.9)\end{array}$ & 0.12 & 0.19 & 0.55 \\
\hline Eccentricity $\left(\varepsilon^{2}\right)$ & $\begin{array}{l}0.22 \pm 0.1 \\
(-0.05 ; 0.5)\end{array}$ & $\begin{array}{l}0.3 \pm 0.3 \\
(-0.6 ; 1.1)\end{array}$ & $\begin{array}{l}0.92 \pm 0.8 \\
(-1.5 ; 2.81)\end{array}$ & 0.30 & $<0.001$ & $<0.001$ \\
\hline I-S value & $\begin{array}{l}0.58 \pm 0.4 \\
(0 ; 1.95)\end{array}$ & $\begin{array}{l}1.41 \pm 0.8 \\
(0.13 ; 2.8)\end{array}$ & $\begin{array}{l}8.44 \pm 4.3 \\
(0.9 ; 24.7)\end{array}$ & 0.004 & $<0.001$ & $<0.001$ \\
\hline Posterior surface & & & & & & \\
\hline Axial Ks (D) & $\begin{array}{l}-6.38 \pm 0.2 \\
(-7.2 ;-5.7)\end{array}$ & $\begin{array}{l}-6.37 \pm 0.3 \\
(-7.2 ;-5.8)\end{array}$ & $\begin{array}{l}-7.3 \pm 0.8 \\
(-10.1 ;-5.6)\end{array}$ & 0.89 & $<0.001$ & $<0.001$ \\
\hline Axial Kf (D) & $\begin{array}{l}-6.08 \pm 0.2 \\
(-6.7 ;-5.5)\end{array}$ & $\begin{array}{l}-6.05 \pm 0.2 \\
(-6.7 ;-5.6)\end{array}$ & $\begin{array}{l}-6.6 \pm 0.7 \\
(-9 ;-5.35)\end{array}$ & 0.80 & $<0.001$ & $<0.001$ \\
\hline Cylinder (D) & $\begin{array}{l}-0.3 \pm 0.11 \\
(-0.7 ;-0.1)\end{array}$ & $\begin{array}{l}-0.3 \pm 0.16 \\
(-0.7 ;-0.1)\end{array}$ & $\begin{array}{l}-0.7 \pm 0.3 \\
(-1.7 ;-0.1)\end{array}$ & 0.99 & $<0.001$ & $<0.001$ \\
\hline Axial MeanK (0-4 mm) & $\begin{array}{l}-6.23 \pm 0.2 \\
(-7 ;-5.66)\end{array}$ & $\begin{array}{l}-6.2 \pm 0.3 \\
(-6.9 ;-5.7)\end{array}$ & $\begin{array}{l}-7.05 \pm 0.8 \\
(-9.8 ;-5.5)\end{array}$ & 0.82 & $<0.001$ & $<0.001$ \\
\hline Tang MeanK (4-7 mm) & $\begin{array}{l}-5.86 \pm 0.2 \\
(-6.6 ;-5.2)\end{array}$ & $\begin{array}{l}-5.7 \pm 0.4 \\
(-6.6 ;-4.9)\end{array}$ & $\begin{array}{l}-5.2 \pm 0.7 \\
(-7 ;-3.2)\end{array}$ & 0.06 & $<0.001$ & $<0.001$ \\
\hline Tang MeanK (7-10 mm) & $\begin{array}{l}-5.25 \pm 0.2 \\
(-5.8 ;-4.5)\end{array}$ & $\begin{array}{l}-5.1 \pm 0.4 \\
(-5.7 ;-4.2)\end{array}$ & $\begin{array}{l}-4.5 \pm 0.8 \\
(-6 ;-1.6)\end{array}$ & 0.03 & $<0.001$ & $<0.001$ \\
\hline Eccentricity $\left(\varepsilon^{2}\right)$ & $\begin{array}{l}0.19 \pm 0.19 \\
(-0.2 ; 0.8)\end{array}$ & $\begin{array}{l}0.32 \pm 0.3 \\
(-0.4 ; 1.09)\end{array}$ & $\begin{array}{l}1.3 \pm 0.96 \\
(-1.3 ; 3.6)\end{array}$ & 0.14 & $<0.001$ & $<0.001$ \\
\hline ISPS & $\begin{array}{l}27.8 \pm 18.9 \\
(0 ; 73.3)\end{array}$ & $\begin{array}{l}94.0 \pm 78 \\
(0 ; 302.6)\end{array}$ & $\begin{array}{l}524 \pm 348 \\
(9.2 ; 2173)\end{array}$ & $<0.001$ & $<0.001$ & $<0.001$ \\
\hline Corneal power (CP) & & & & & & \\
\hline TCP $(0-4 \mathrm{~mm})$ & $\begin{array}{l}41.7 \pm 1.2 \\
(38 ; 44.8)\end{array}$ & $\begin{array}{l}41.8 \pm 1.5 \\
(37.9 ; 44.9)\end{array}$ & $\begin{array}{l}45.2 \pm 3.7 \\
(36 ; 60.2)\end{array}$ & 0.47 & $<0.001$ & $<0.001$ \\
\hline TCP (4-7 mm) & $\begin{array}{l}42.2 \pm 1.3 \\
(38.8 ; 45.6)\end{array}$ & $\begin{array}{l}42.2 \pm 1.5 \\
(39.5 ; 44.9)\end{array}$ & $\begin{array}{l}44.3 \pm 2.2 \\
(39.3 ; 51.5)\end{array}$ & 0.33 & $<0.001$ & $<0.001$ \\
\hline TCP (7-10 mm) & $\begin{array}{l}42.6 \pm 1.5 \\
(39.1 ; 45.9)\end{array}$ & $\begin{array}{l}42.4 \pm 1.7 \\
(39 ; 45.3)\end{array}$ & $\begin{array}{l}43.9 \pm 2 \\
(38.4 ; 51.5)\end{array}$ & 0.68 & $<0.001$ & $<0.001$ \\
\hline
\end{tabular}

FFKCN: Forme fruste keratoconus; KCN: Keratoconus; SD: Standard deviation; Ks: SteepestK; Kf: Flattest K; Cyl: Cylinder (D); MeanK: Average keratometry (D); Tang: Tangential map; I-S: Inferior-superior ratio; ISPS: I-S posterior score; TCP: Total corneal power; OSI: Opposite sector index. Note-Bold: Statistically significant

the most discriminant with 11 variables out of the 14 that were significantly different. The maximum anterior elevation (M AE) and maximum posterior elevation (MPE) calculated relative to a BFS were not different between normal corneas and FFKC, whereas it was significantly different when calculated relative to a BFTA reference surface ( $T$ able 4). Curvature-derived parameters relative to the anterior surface were not significantly different between 
Comparative Evaluation of Elevation, Keratometric, Pachymetric and Wavefront Parameters in Normal Eyes

Table 4: Elevation-derived parameters and pachymetric data: Means and intergroup comparison

\begin{tabular}{|c|c|c|c|c|c|c|}
\hline \multirow[t]{2}{*}{ N (n subjects) } & \multicolumn{3}{|c|}{ Means \pm SD (min; max) } & \multicolumn{3}{|c|}{ Intergroup comparisons mixed model ( $p$-value) } \\
\hline & $\begin{array}{l}\text { Normal } \\
177(n=95)\end{array}$ & $\begin{array}{l}\text { FFKCN } \\
47(n=47)\end{array}$ & $\begin{array}{l}\text { KCN } \\
148(n=102)\end{array}$ & $\mathrm{N}$ vs FFKCN & $\mathrm{N}$ vs $\mathrm{KCN}$ & FFKCN vs KCN \\
\hline \multicolumn{7}{|l|}{ Anterior surface } \\
\hline BFTA MAETP & $\begin{array}{l}0.44 \pm 1.4 \\
(-4 ; 5)\end{array}$ & $\begin{array}{l}2.21 \pm 2.8 \\
(-4 ; 13)\end{array}$ & $\begin{array}{l}17.5 \pm 12 \\
(-7 ; 58)\end{array}$ & 0.06 & $<0.001$ & $<0.001$ \\
\hline BFTA MAEKm & $\begin{array}{l}2.4 \pm 2.2 \\
(-2 ; 10)\end{array}$ & $\begin{array}{l}4.9 \pm 4.1 \\
(-2 ; 16)\end{array}$ & $\begin{array}{l}23.8 \pm 15.1 \\
(-1 ; 69)\end{array}$ & 0.03 & $<0.001$ & $<0.001$ \\
\hline BFTA MAE & $\begin{array}{l}4.8 \pm 1.7 \\
(1 ; 9)\end{array}$ & $\begin{array}{l}8.4 \pm 3.9 \\
(1 ; 19)\end{array}$ & $\begin{array}{l}31.9 \pm 15.8 \\
(6 ; 87)\end{array}$ & 0.03 & $<0.001$ & $<0.001$ \\
\hline BFS MAETP & $\begin{array}{l}1.55 \pm 1.4 \\
(-2 ; 8)\end{array}$ & $\begin{array}{l}3.3 \pm 2.5 \\
(-1 ; 11)\end{array}$ & $\begin{array}{l}17.9 \pm 10.8 \\
(-2 ; 56)\end{array}$ & 0.04 & $<0.001$ & $<0.001$ \\
\hline BFS MAEKm & $\begin{array}{l}1.36 \pm 1.7 \\
(-8 ; 7)\end{array}$ & $\begin{array}{l}3.2 \pm 2.9 \\
(-2 ; 12)\end{array}$ & $\begin{array}{l}18.1 \pm 11.8 \\
(2 ; 60)\end{array}$ & 0.04 & $<0.001$ & $<0.001$ \\
\hline BFS MAE & $\begin{array}{l}5.4 \pm 3.15 \\
(0 ; 15)\end{array}$ & $\begin{array}{l}7.2 \pm 4.3 \\
(2 ; 20)\end{array}$ & $\begin{array}{l}25.2 \pm 12.5 \\
(6 ; 64)\end{array}$ & 0.2 & $<0.001$ & $<0.001$ \\
\hline AAI anterior & $\begin{array}{l}9.2 \pm 3.6 \\
(0 ; 27)\end{array}$ & $\begin{array}{l}15.8 \pm 6.9 \\
(3 ; 33)\end{array}$ & $\begin{array}{l}54.4 \pm 26.2 \\
(13 ; 150)\end{array}$ & 0.01 & $<0.001$ & $<0.001$ \\
\hline Posterior surface & & & & & & \\
\hline BFTA MPETP & $\begin{array}{l}-0.84 \pm 2.4 \\
(-9 ; 5)\end{array}$ & $\begin{array}{l}3.55 \pm 6.6 \\
(-9 ; 32)\end{array}$ & $\begin{array}{l}35.9 \pm 24.9 \\
(-11 ; 107)\end{array}$ & 0.02 & $<0.001$ & $<0.001$ \\
\hline BFTA MPEKm & $\begin{array}{l}3.3 \pm 4 \\
(-9 ; 14)\end{array}$ & $\begin{array}{l}9.7 \pm 8.4 \\
(-10 ; 27)\end{array}$ & $\begin{array}{l}43.1 \pm 27.3 \\
(1 ; 135)\end{array}$ & 0.005 & $<0.001$ & $<0.001$ \\
\hline BFTA MPE & $\begin{array}{l}8.6 \pm 2.8 \\
(4 ; 17)\end{array}$ & $\begin{array}{l}16.9 \pm 6.9 \\
(4 ; 39)\end{array}$ & $\begin{array}{l}57.8 \pm 28.4 \\
(10 ; 135)\end{array}$ & 0.004 & $<0.001$ & $<0.001$ \\
\hline BFS MPETP & $\begin{array}{l}2.3 \pm 2.4 \\
(-3 ; 11)\end{array}$ & $\begin{array}{l}7.4 \pm 6.7 \\
(-3 ; 32)\end{array}$ & $\begin{array}{l}38.2 \pm 21.5 \\
(3 ; 109)\end{array}$ & 0.01 & $<0.001$ & $<0.001$ \\
\hline BFS MPEKm & $\begin{array}{l}0.9 \pm 4.2 \\
(-25 ; 10)\end{array}$ & $\begin{array}{l}6.8 \pm 6.7 \\
(-5 ; 24)\end{array}$ & $\begin{array}{l}33.7 \pm 20.5 \\
(-9 ; 103)\end{array}$ & 0.002 & $<0.001$ & $<0.001$ \\
\hline BFS MPE & $\begin{array}{l}13.1 \pm 5.2 \\
(3 ; 30)\end{array}$ & $\begin{array}{l}15.4 \pm 6.5 \\
(3 ; 34)\end{array}$ & $\begin{array}{l}46 \pm 20.6 \\
(6 ; 109)\end{array}$ & 0.2 & $<0.001$ & $<0.001$ \\
\hline AAI posterior & $\begin{array}{l}16.76 \pm 5 \\
(0 ; 36)\end{array}$ & $\begin{array}{l}31.1 \pm 12.3 \\
(7 ; 66)\end{array}$ & $\begin{array}{l}99.8 \pm 49.2 \\
(20 ; 250)\end{array}$ & 0.002 & $<0.001$ & $<0.001$ \\
\hline Pachymetric data & & & & & & \\
\hline Thinnest point & $\begin{array}{l}550 \pm 25 \\
(505 ; 630)\end{array}$ & $\begin{array}{l}520 \pm 29.4 \\
(450 ; 575)\end{array}$ & $\begin{array}{l}478.3 \pm 39 \\
(313 ; 565)\end{array}$ & $<0.001$ & $<0.001$ & $<0.001$ \\
\hline Corneal volume & $\begin{array}{l}33.6 \pm 1.5 \\
(30.9 ; 38.5)\end{array}$ & $\begin{array}{l}31.9 \pm 1.7 \\
(28.3 ; 35.9)\end{array}$ & $\begin{array}{l}31.2 \pm 1.7 \\
(25.2 ; 35.4)\end{array}$ & $<0.001$ & $<0.001$ & $<0.001$ \\
\hline
\end{tabular}

FFKCN: Forme fruste keratoconus; KCN: Keratoconus; SD: Standard deviation; BFTA: Best-fit toric aspheric surface; BFS: Best-fit sphere; MAETP: Maximum anterior elevation at the thinnest point; MAE Km: Maximum anterior elevation at the $\mathrm{K}_{\max }$; MAE: Maximum anterior elevation; MPETP: Maximum posterior elevation at the thinnest point; MPE Km: Maximum posterior elevation at the $K_{\text {max; }}$ MPE: Maximum posterior elevation; AAI: Asphericity asymmetry index. Note-Bold: Statistically significant

the two groups, except for the I-S value $(p=0.004)$ and $\mathrm{K}_{\max }(p=0.01)$. At the posterior surface, the ISPS was significantly greater in FFK C than in normal eyes, with 94.0 \pm 78 and $27.8 \pm 18.9$ respectively in the FFK C group and in the normal group. The RMS vertical coma was the only corneal aberration significantly different between the two groups, with a mean of $-0.35 \mu \mathrm{m}$ in the FFKC group and $0.01 \mu \mathrm{m}$ in the normal group. Pachymetric derived parameters (thinnest point and corneal volume) were significantly different between the two groups with thinner corneas and a lower corneal volume in the FFKC group. All the intergroup comparisons are shown in Tables 3 to 5 .

\section{DISCUSSION}

While discriminating between normal corneas and keratoconus is no longer a problem with the current corneal imaging technologies, identifying subclinical keratoconus remains the most challenging situation faced by the ophthalmologist when considering a refractive surgery procedure. In the present study, our results obtained with the GA LILEI analyzer corroborate this finding, with nearly $90 \%(38 / 43)$ of the parameters analyzed that were significantly different between normal corneas and keratoconus compared to only 39\% (17/43) between normal and FFKC. A ccording to our results, the variables that were the most differents between normal corneas from FFKC were related to corneal elevation, with 11 variables out of 14 that were significantly different. Interestingly, the M A E and M PE calculated relative with a BFS were not different between both groups whereas it was significantly different when calculated relative to a B FTA. In a previous work of our group, we demonstrated that the use of a BFTA reference 
Table 5: Wavefront and biometric parameters: Means and intergroup comparison

\begin{tabular}{|c|c|c|c|c|c|c|}
\hline \multirow[t]{2}{*}{$\mathrm{N}$ (n subjects) } & \multicolumn{3}{|c|}{ Mean \pm SD (min; $\max )$} & \multicolumn{3}{|c|}{ Intergroup comparisons mixed model ( $p$-value) } \\
\hline & $\begin{array}{l}\text { Normal } \\
177(n=95)\end{array}$ & $\begin{array}{l}\text { FFKCN } \\
47(n=47)\end{array}$ & $\begin{array}{l}\text { KCN } \\
148(n=102)\end{array}$ & $\mathrm{N}$ vs FFKCN & $\mathrm{N}$ vs $\mathrm{KCN}$ & FFKCN vs KCN \\
\hline \multicolumn{7}{|l|}{ Corneal wavefront $(\mu)$} \\
\hline RMS total HOA & $\begin{array}{l}0.53 \pm 0.16 \\
(0.2 ; 1)\end{array}$ & $\begin{array}{l}0.76 \pm 0.26 \\
(0.3 ; 1.52)\end{array}$ & $\begin{array}{l}2.71 \pm 1.3 \\
(0.66 ; 8.2)\end{array}$ & 0.08 & $<0.001$ & $<0.001$ \\
\hline RMS SA & $\begin{array}{l}0.22 \pm 0.1 \\
(0.03 ; 0.4)\end{array}$ & $\begin{array}{l}0.18 \pm 0.17 \\
(-0.2,0.6)\end{array}$ & $\begin{array}{l}-0.1 \pm 0.57 \\
(-1.8,1.2)\end{array}$ & 0.46 & $<0.001$ & $<0.001$ \\
\hline RMS vertical coma & $\begin{array}{l}0.01 \pm 0.2 \\
(-0.5 ; 0.68)\end{array}$ & $\begin{array}{l}-0.35 \pm 0.4 \\
(-1.2 ; 0.32)\end{array}$ & $\begin{array}{l}-2.1 \pm 1.3 \\
(-7.66 ; 0.9)\end{array}$ & 0.006 & $<0.001$ & $<0.001$ \\
\hline RMS horizontal coma & $\begin{array}{l}-0.01 \pm 0.3 \\
(-0.8 ; 0.8)\end{array}$ & $\begin{array}{l}-0.04 \pm 0.34 \\
(-0.7 ; 0.8)\end{array}$ & $\begin{array}{l}0.01 \pm 0.94 \\
(-4.4 ; 3.2)\end{array}$ & 0.84 & 0.81 & 0.71 \\
\hline RMS total coma & $\begin{array}{l}0.35 \pm 0.2 \\
(0.02 ; 0.9)\end{array}$ & $\begin{array}{l}0.55 \pm 0.28 \\
(0.07 ; 1.3)\end{array}$ & $\begin{array}{l}2.27 \pm 1.26 \\
(0.45 ; 7.7)\end{array}$ & 0.07 & $<0.001$ & $<0.001$ \\
\hline $\begin{array}{l}\text { Biometric data } \\
\text { AC depth }\end{array}$ & $\begin{array}{l}3.2 \pm 0.3 \\
(2.4 \cdot 38)\end{array}$ & $\begin{array}{l}3.2 \pm 0.3 \\
(24 \cdot 38)\end{array}$ & $3.3 \pm 0.3$ & & & \\
\hline AC volume & $\begin{array}{l}(2.4 ; 3.8) \\
120.6 \pm 23.4 \\
(44 ; 268)\end{array}$ & $\begin{array}{l}(2.4 ; 3.8) \\
116.8 \pm 22.1 \\
(65 ; 164)\end{array}$ & $\begin{array}{l}(2.6 ; 3.9) \\
118.3 \pm 15.6 \\
(84 ; 151)\end{array}$ & 0.27 & 0.42 & $\begin{array}{l}<0.001 \\
0.60\end{array}$ \\
\hline
\end{tabular}

FFKCN: Forme fruste keratoconus; KCN: Keratoconus; SD: Standard deviation; HOA: Higher order aberrations; SA: S pherical aberrations; AC: Anterior chamber. Note 1-Bold: Statistically significant. Note 2-Corneal aberrations for $6 \mathrm{~mm}$ pupil diameter.

surface for calculating elevation improved the sensitivity of subclinical keratoconus detection compared to that with a BFS. ${ }^{14}$ The optimized cutoff val ue for best differentiating normal corneas from FFKC was set at $13 \mu \mathrm{m}$ of posterior elevation in the BFTA display. By matching closer to the natural toric and aspherical shape of the cornea, the BFTA allows to neutralize the ridge pattern commonly seen in elevation maps calculated relative to BFS and due to the effect of corneal toricity ${ }^{15,16}$ and therefore might help revealing more sensitively the first signs of asymmetry in elevation. This difference between the BFS and BFTA displays becomes particularly relevant when tracking subtle abnormalities in elevation maps for detecting subclinical keratoconus.

A nother interesting finding is that curvature-derived parameters related to the anterior corneal surface were mostly not significantly different between normal and FFKC with only two variables (I-S value and $\mathrm{K}_{\max }$ ) out of nine, which is not surprising given the exact definition of the FFKC that implies a topographically normal cornea. Although corneal topography has been found sensitive for detecting keratoconus prior to clinical biomicroscopic findings, it has reported evidences of subclinical keratoconus in corneas undergoing tomographic analysis while they were considered normal by the various topographic keratoconus detection indices. ${ }^{4,17}$ This finding further feeds the debate on the location of the first detectable sign of subclinical keratoconus, whether it would be subtle changes in anterior surface curvature seen with Placido disk or posterior surface changes detected only by tomography. Placido disk technology is exclusively limited to the anterior surface analysis and several recent studies have pointed out the ability that has the epithelium to remodel itself to compensate for stromal surface abnormalities, which can mask the presence of an underlying cone on the anterior surface in early keratoconus. ${ }^{2,3}$ In contrast, corneal tomography, which allows for a more complete analysis of the corneal properties, such as elevation-derived parameters, posterior surface analysis, pachymetric spatial profile or wavefront analysis has already been successfully used in multiples studies for improving the sensitivity of subclinical keratoconus detection. Schlegel et al have reported significant greater posterior astigmatism, posterior el evation and a more prolate posterior surface in keratoconus suspect eyes compared to normal eyes by using the Orbscan $\mathrm{IIz}$ system. ${ }^{18}$ Pinero et al have later supported this finding with another system, the Pentacam (O culus). ${ }^{8} \mathrm{~N}$ ilforoushan et al performed a multiple regression analysis and have identified the larger difference betw een the highest and low est points on the posterior elevation maps with both Pentacam and Orbsacn IIz system, as the strongest predictor of suspect keratoconus. ${ }^{19}$ Similarly, in the present study, we found a strong statistical difference $(p<0.001)$ in the posterior A A I between normal corneas and FFK $C$, which is al so calculated as the absolute difference between the highest and the lowest elevation value but in the posterior BFTA elevation map, which further supports the finding of Nilforoushan et al. These recent findings in the field of keratoconus detection have all contributed to point out the clinical significance of the posterior surface modifications and to consider it as a key variable in the subclinical keratoconus screening process.

Corneal thinning has also been shown to be a key pathologic feature of keratoconus. ${ }^{19,20}$ In our study, the 
Comparative Evaluation of Elevation, Keratometric, Pachymetric and Wavefront Parameters in Normal Eyes

pachymetric indices were found significantly different between normal corneas, FFKC and keratoconus, with a progressive thinning along with the progression of the ectatic process. Previous studies have already reported thinner corneas in suspect keratoconus than in normal eyes ${ }^{18,19}$ and a progressive thinning along with the progression of the disease. ${ }^{8}$ To go even further, Saad and Gatinel have recently calculated with the O rbscan system, the percentage increase in thickness (PIT), that was described by A mbrosio et al with the Pentacam, ${ }^{21}$ and reported a significantly higher PIT in the most incipient form of the keratoconus disease (FFKC) than in normal corneas. ${ }^{4}$ This finding suggests that subclinical form of keratoconus might be characterized not only by thinner corneas but also by a quick modification of the corneal thickness from the thinnest point to the periphery.

In the present work, we found that vertical coma was the only corneal aberration that was significantly different $(p=0.006)$ between normal corneas and FFK C with a means of $0.01 \mu \mathrm{m}$ and $-0.35 \mu \mathrm{m}$, respectively. This finding is in agreement with recent reports showing that the anterior corneal vertical coma had a strong ability to discriminate between normal corneas and subclinical keratoconus. ${ }^{22,23}$ Corneal vertical coma has even been incorporated recently in a new keratoconus classification for grading the disease. ${ }^{24}$

By providing precious information on corneal properties, such as anterior and posterior el evation data, pachymetric and wavefront profile, the GA LILEI analyzer has shown to be a useful imaging system for differentiating between normal corneas, subclinical keratoconus and keratoconic corneas, similarly to other imaging systems. However, as previously shown in the literature, ${ }^{25,26}$ although, differences in corneal features have been demonstrated between normal and FFKC, it remains that one parameter alone can hardly reach a high discriminative ability for differentiating normal eyes from subclinical keratoconus. Therefore, the most discriminant parameters provided by the Dual Scheimpflug A nalyzer should be combined in a single discriminant function to provide a more sensitive detection program for identifying corneas at risk of ectasia.

\section{REFERENCES}

1. Gatinel D, Racine L, Hoang-X uan T. Contribution of the corneal epithelium to anterior corneal topography in patients having myopic photorefractive keratectomy. J Cataract Refract Surg 2007;33(11):1860-65.

2. Reinstein DZ, Cantab M A, Gobbe M, et al. Epithelial, stromal, and total corneal thickness in keratoconus: Three-dimensional display with artemis very-high frequency digital ultrasound. J Refract Surg 2010;26(4):259-72.

3. Touboul D, Trichet E, Binder PS, et al. Comparison of frontsurface corneal topography and Bowman membrane specular topography in keratoconus. J Cartaract Refract Surg 2012;38(6):1043-49.

4. Saad A, Gatinel D. Topographic and tomographic properties of forme fruste keratoconus corneas. Invest Ophthalmol V is Sci 2010;51(11):5546-55.

5. A mbrósio R, Alonso RS, Luz A, Guillermo L, V elarde C. Corneal-thickness spatial profile and corneal-volume distribution: Tomographic indices to detect keratoconus. J Cartaract R efract Surg 2006 N ov;32:1851-59.

6. A mbrósio R, Caiado A LC, et al. Novel pachymetric parameters based on corneal tomography for diagnosing keratoconus. J Refract Surg 2011;27(10):753-58.

7. Bühren J, K ook D, Y oon G, K ohnen T. Detection of subclinical keratoconus by using corneal anterior and posterior surface aberrations and thickness spatial profiles. Invest Ophthalmol $V$ is Sci 2010;51(7):3424-32.

8. Piñero DP, A lió J L, A lesón A, Escaf Vergara M, M iranda M. Corneal volume, pachymetry, and correlation of anterior and posterior corneal shape in subclinical and different stages of clinical keratoconus. J Cataract Refract Surg 2010;36(5):81425.

9. A rbelaez M C, V ersaci F, V estri G, B arboni P, Savini G. U se of a support vector machine for keratoconus and subclinical keratoconus detection by topographic and tomographic data. Ophthalmology 2012;119:2231-38.

10. Li X, Rabinowitz Y S, Rasheed K, Y ang H. L ongitudinal study of the normal eyes in unilateral keratoconus patients. Ophthalmology 2004;111(3):440-46.

11. Rabinowitz Y S. K eratoconus. Surv Ophthalmol 1998;42(4):297319.

12. Zadnik K, B arr J T, Edrington TB, et al. B aseline findings in the collaborative longitudinal evaluation of keratoconus (CLEK) study. Invest Ophthalmol V is Sci 1998;39:2537-46.

13. A rceC. Q ualitative and quantitative analysis of aspheric symmetry and asymmetry on corneal surfaces. Boston (MA): Electronic Poster, A SCR S Symposium and Congress 2010 A pril; 9-14.

14. Smadja D, Santhiago MR, M ello GR, et al. Influence of the reference surface shape for discriminating between normal corneas, subclinical keratoconus and keratoconus. J R efract Surg 2013 (In review).

15. Gatinel D, Malet J, Hoang-xuan T. Corneal elevation topography: Best fit sphere, elevation distance, asphericity, toricity and clinical implications. Cornea 2011;30(5):508-15.

16. K ovács I, M ihált K, Ecsedy M, N émeth J, N agy ZZ. The role of reference body selection in calculating posterior corneal elevation and prediction of keratoconus using rotating Scheimpflug camera. A cta ophthalmologica 2011;89(3):e25156.

17. B elin M W , A mbrosio R. Corneal ectasia risk score: Statistical validity and clinical relevance. J R efract Surg 2010;26(4):23841.

18. Schlegel Z, Hoang-xuan T, Gatinel D. Comparison of and correlation between anterior and posterior corneal elevation maps in normal eyes and keratoconus-suspect eyes. J Refract Surg 2007:789-95.

19. Nilforoushan $M-R$, Speaker $M, M$ armor $M$. Comparative evaluation of refractive surgery candidates with Placido topography, Orbscan II, Pentacam and wavefront analysis. J Cartaract R efract Surg 2008;34:623-31.

20. Lim L, W ei RH, Chan WK , Tan DTH. Evaluation of keratoconus in A sians: role of Orbscan II and Tomey TM S-2 corneal topography. A m J O phthalmol 2007;143(3):390-400. 
21. A mbrósio R J r. Percentage thickness increase and absolute difference from thinnest to describe thickness profile. J R efract Surg 2010 Feb;26(2):84-86.

22. Bühren J, K ühne C, K ohnen T. D efining subclinical keratoconus using corneal first-surface higher-order aberrations. A m J Ophthalmol 2007;143(3):381-89.

23. Saad A, Gatinel D. Evaluation of total and corneal wavefront high order aberrations for the detection of forme fruste keratoconus. Invest Ophthalmol V isual Sci 2012;(C):2978-92.

24. Alió JL, Shabayek M H. Corneal higher order aberrations: A method to grade keratoconus. J Refract Surg 2006;22(J une):539-46.

25. Saad A, Gatinel D. A ssociation of corneal indices for the detection of ectasia-susceptible corneas. J R efract Surg 2012;28(3):166-67.

26. U çakhan ÖÖ, Cetinkor V, Özkan M, K anpolat A. Evaluation of Scheimpflug imaging parameters in subclinical keratoconus, keratoconus, and normal eyes. J Cataract Refract Surg 2011;37(6):1116-24.

\section{ABOUT THE AUTHORS}

\section{David Smadja (Corresponding Author)}

Ophthalmologist, D epartment of O phthalmology, A nterior Segment and R efractive Surgery U nit, U niversity H ospital of B ordeaux, F rance e-mail: davidsmadj@ hotmail.fr

\section{David Touboul}

Ophthalmologist, Department of O phthalmology, A nterior Segment and R efractive Surgery U nit, U niversity H ospital of B ordeaux, F rance

\section{Joseph Colin}

Professor, Department of Ophthalmology, A nterior Segment and Refractive Surgery U nit, U niversity Hospital of B ordeaux, France 